\title{
The Use Of MEWMA Control Chart In Controlling Major Component Of Cement Product
}

\author{
$1^{\text {st }}$ Surya Puspita Sari ${ }^{1}, 2^{\text {nd }}$ Dodi Devianto ${ }^{2}$ \\ \{surya.p.sari@gmail.com ${ }^{1}$, ddevianto@sci.unand.ac.id ${ }^{2}$ \} \\ Department of Mathematics, Andalas University, Padang, 25163, Indonesia ${ }^{1,2}$
}

\begin{abstract}
Cement is one of the industrial products that has a quality control process. Major component that consists of $\mathrm{SiO}_{2}, \mathrm{Al}_{2} \mathrm{O}_{3}, \mathrm{Fe}_{2} \mathrm{O}_{3}, \mathrm{CaO}, \mathrm{MgO}$ and $\mathrm{SO}_{3}$ as basic component in cement product. This research explains about quality control of major component of cement by using MEWMAcontrol chart. The way to measure the performance of the control chart is used ARL as the average run observation to find the first out of control data. ParameterARL $\mathrm{A}_{0}$ is the average run observation of in control data. In this research, it is assumed the data was in control. The optimization of $\mathrm{ARL}_{0}$ by weighted parameter of MEWMA control chart for $\lambda=1$, that is equal to Hotteling $\mathrm{T}^{2}$ chart. Optimal value of the weight parameter is determined by using the bisection method for then the variables did not show the outlier data. Finally, this research shows that cement production process is in control.
\end{abstract}

\begin{abstract}
Keywords: average run length,multivariate exponentially weighted moving
\end{abstract} average control chart, weightedparameter

\section{Introduction}

Nowadays the competitive market implies companies to develop their production and servicing system improving the costumer's satisfaction. In first quarter financial performance report 2019 announced the cement financial income has increased from the previous year by Pers Conference Indonesian Cement [1]. Indonesia's cement sales performance also experienced an increase in the total volume of domestic sales and exports.

The company of cement prepares the quality and efficiency of cement. The quality of cement was influenced by basic component as the raw material. Therefore, it needs the controlling of basic components or usually called major component of cement as raw material for the number one of cement production. As the other companies industry, the company of cement must have constantly to control the quality of cement to produce products that meet a standard. There are controlling variables in cement company's raw material that established by SNI (Indonesian National Standard). In this case, the raw material is the major component in cement production. They are Silicon Dioxide ( $\mathrm{SiO} 2)$, Aluminium Oxide (Al2O3), Iron(III) Oxide (Fe2O3), Oxocalcium ( $\mathrm{CaO}$ ), Magnesium Oxide ( $\mathrm{MgO})$ and Sulfur Trioxide (SO3) as the independent variable in this research.

The way of statistical quality control techniques is control chart as monitoring product quality of production process. In the some research, it is usually influenced by several variables. These variables often correlate with one another. Therefore, a diagram is made that is designed to discuss the structure between variables and research the variables that are correlated in a research that is in accordance with the controlled situation or not. The data used in research is often time series data. So the UnivariateWeighted Moving Average control chart 
is used for data with one variable. Whereas the data condition has many variables, then the Multivariate EWMA control diagram is used.

Multivariate EWMA (MEWMA) control chart is a control chart to detect small changes in a process mean vector [2]. Developed by Lowry et al. [3], the MEWMA chart is the multivariate extension of the EWMA chart. According to Borror et al. [4], the EWMA chart also performs quite well in detecting shift in the process mean. Khan. $\mathrm{N}$ et al. [5] explain that EWMA control chart for monitoring exponential distributed quality characteristics where the exponential distribution contained the characteristic function and term of convolution had researched by Devianto [6] and [7]. The sum of exponential distribution is the hypoexponential distribution can setting by stabilizer constant such as describe by Devianto et al. [8] and [9]. TheMEWMA control chart is used to simultaneously monitor several correlated process variables [10]. A simulation study to investigate the sensitivity of multivariate control charts, such as Hotteling $\mathrm{T}^{2}$, MCUSUM and MEWMA chart for monitoring mean vectors in bivariate Gaussian process with individual observations was discussed by Moreaes et al. [11] and estimating the vector of means and variance-covariance matrix was explained with Mahmoud et al. [12]. MEWMA control procedure had been research with DD-Diagram performance to compare through a real example on individual observations taken from a multivariate quality process also discussed by Hajlaoui [13]. The high costs of implementing MEWMA control chart, the economic statistical design of this chart has been increasingly investigated had been explained with Amiri et al. [14]. Hamed [15] and Knoth [16] find the ARL numeric for MEWMA charts.

Major component as the raw material of cement has six variables as the quality variables in this research. The MEWMA control chart is a control chart that use in this research because has one more variables and the level precision is high. The effective MEWMA control chart is obtained by small weight value. So that, this study will examine about the use of MEWMA control chart in controlling major component of PCC cement product.

\section{MEWMA Control Chart}

The MEWMA control chart is generalized for univariate EWMA to multivariate case. In this research, will be used MEWMA control chart for individual observation. Lowry [3] defined the MEWMA vector as

$$
\begin{aligned}
& Z_{i}=\Lambda X_{i}+(1-\Lambda) Z_{i-1}, \quad i=1,2, \cdots \\
& \Lambda=\operatorname{diag}\left(\lambda_{1}, \lambda_{2}, \cdots, \lambda_{p}, 0<\lambda_{j} \leq 1\right), j=1,2, \cdots, p \text { and } p>1,
\end{aligned}
$$

where $\Lambda$ is a smoothing constant and $Z_{i}$ is the value of the MEWMA after $i$-observation, where $i$ represent the observation number, where we required $Z_{0}=0$ without loss of generality and $0<\Lambda \leq 1$.

The MEWMA control chart gives an out of control signal as soon as:

$$
T_{i}^{2}=Z_{i}^{\prime} \Sigma_{Z_{i}}^{-1} Z_{i}, \text { where } Z_{i}>L
$$


where choose $L>0$ is a specified in-control $A R L$ and $\Sigma_{Z_{i}}$ is the covariance matrix of $Z_{i}$.

Often there is no reason to apply different exponential weight to past observations of the $p$ different quality characteristics. In this situation, it is assumed the equal weights across characteristics where $r=r_{j}, j=1, \cdots, p$, the MEWMA vectors can be written as:

$$
Z_{i}=\lambda X_{i}+(1-\lambda) Z_{i-1}, \quad i=1,2, \cdots
$$

where $Z_{i}$ is MEWMA vector and $\lambda$ is weight of MEWMA, $0<\lambda \leq 1$.

The following illustrated MEWMA control chart using $p$ variables and $n$ observations. Input data is the matrix below:

$$
X=\left(\begin{array}{cccc}
x_{11} & x_{12} & \cdots & x_{1 p} \\
x_{21} & x_{22} & \cdots & x_{2 p} \\
\vdots & \vdots & \vdots & \vdots \\
x_{n 1} & x_{n 2} & \cdots & x_{n p}
\end{array}\right)
$$

where $X$ is matrix size $n \times p$ to show many data until $n$-observation and $p$-variable, $x_{i j}=$ data on $i$ - observation and $j$ - variable, $i=1,2, \ldots, n$ and $j=1,2, \ldots, p$. In other that $X_{\mathrm{i}}$ can be defined as follows as:

$$
X_{i}=\left(x_{i 1}, x_{i 2}, \cdots, x_{i p}\right)^{\prime}
$$

where $X_{i}$ is vector valued output at observation $i=1,2, \ldots$

Under the assumption of equal weight, the covariance matrix of $Z_{i}$ can be written in terms of the exponential weight $(\lambda)$ and the covariance matrix of the process data $\Sigma_{X}$ as:

$$
\Sigma_{Z_{i}}=\frac{\lambda}{2-\lambda}\left[1-(1-\lambda)^{2 i}\right] \Sigma_{X}, i=1,2, \cdots, n
$$

and

$$
\Sigma_{X}=\frac{1}{n-1} \sum_{i=1}^{n}\left(X_{i}-\bar{X}\right)\left(X_{i}-\bar{X}\right)^{\prime}
$$

where

$$
\begin{aligned}
& \bar{X}=\left[\bar{x}_{1}, \bar{x}_{2}, \cdots, \bar{x}_{p}\right]^{\prime} \\
& \bar{x}_{j}=\frac{1}{n} \sum_{i=1}^{n} x_{i j}, j=1,2, \cdots, p .
\end{aligned}
$$

Note that if $\lambda=1$, the MEWMA control chart is equivalent to Hotteling $\mathrm{T}^{2}$ chart [15].

The Average Run Length $(A R L)$ is metric used to determine the control chart if the process in control or out of control. The way to measure the performance of the control chart is used Average Run Length (ARL) as the average run observation to found the first out of control data. $\mathrm{ARL}_{0}$ is the average run observation of in control data. In these research, it is assumed the data was in control.

The Upper Center Line (UCL) of MEWMA control chart is as follow:

$$
U C L=H
$$


The value of $\mathrm{H}$ is influenced by variables $(p)$, weight value and $A R L$ under controlled conditions $\left(A R L_{0}\right)$. The controlling data can be constructed using standardized data.

The Lower Center Line (LCL) of MEWMA control chart is as follow:

$$
L C L=0
$$

$L C L$ is zero because $T_{i}$ always positive, so that the minimum control limit is the most minimum from positive value and it is zero. The process can be classified uncontrolled if $T_{i}>U C L$

\section{Method}

\subsection{Data}

In this research, use the data of major component of PCC cement production that consists of $\mathrm{SiO}_{2}, \mathrm{Al}_{2} \mathrm{O}_{3}, \mathrm{Fe}_{2} \mathrm{O}_{3}, \mathrm{CaO}, \mathrm{MgO}$ and $\mathrm{SO}_{3}$ on January until March 2018 .

\subsection{Analysis Method}

This research uses MEWMA control chart. The main purpose of implementing MEWMA control chart is controlling the process based on the mean data against a major component of PCC cement product with the algorithm as follows:

a. Determine the $\mathrm{ARL}_{0}$ value by comparing the MEWMA control chart with Hotteling $\mathrm{T}^{2}$ chart.

b. Define the value of weighted parameter $(\lambda)$.

c. Standardize the data.

d. Measure the variance-covariance matrix based on data.

e. Define the MEWMA control chart, vector and the variance covariance matrix based on $Z_{i}$.

f. Calculate the statistical of MEWMA.

g. Interpretation the MEWMA control chart.

h. Determine EWMA control chart in major component of cement product.

i. Analyze the MEWMA control chart.

\section{Determine of $\mathrm{ARL}_{0}$ in MEWMA Control Chart}

Average run length at the time controlled data is named $\mathrm{ARL}_{0}$ that one of the values that is used in the form of MEWMA control chart MEWMA control chart with $\lambda=1$ is equivalent to Hotteling $\mathrm{T}^{2}$ chart. Therefore, will be determined $\mathrm{ARL}_{0}$ of MEWMA control chart to find $U C L$ of Hotteling $\mathrm{T}^{2}$ chart similar with $U C L$ of MEWMA control chart by using Minitab 17. 


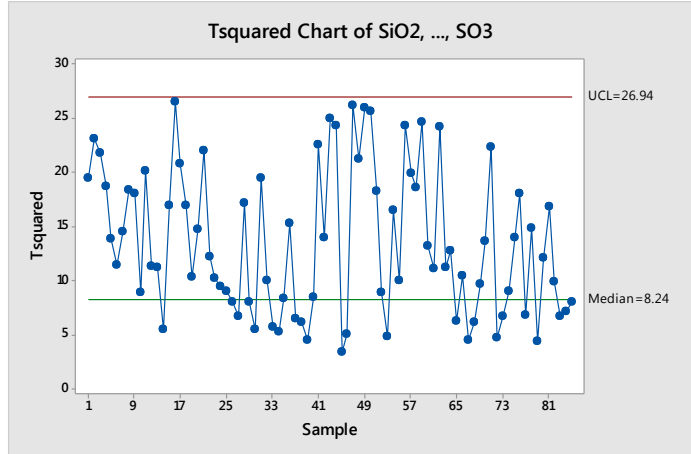

Fig. 1. Hotelling $\mathrm{T}^{2}$ Chart

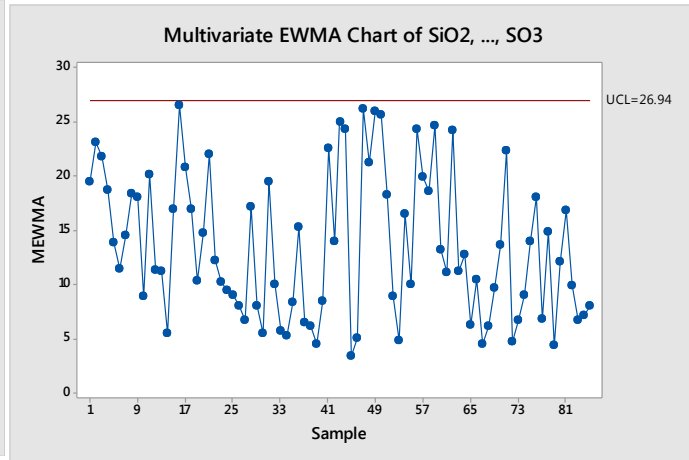

Fig. 2. MEWMA Control Chart with $\mathrm{ARL}_{0}=6740$

Based on Figure 2, we can know that the diagram of MEWMA control chart with $\mathrm{ARL}_{0}=$ 6740 equivalent to Hotelling $\mathrm{T}^{2}$ chart in Figure 1 that is having the same statistical value at each boundary value observation and control limit is the same. Therefore, in this study, writer will choose $\mathrm{ARL}_{0}=6740$.

\section{Implementation of MEWMA Control Chart}

First, finds weight of MEWMA control chart by bisection method. Because the maximum weight of MEWMA control chart is one, then choose $\lambda_{1}=0.5$. Then, the result of MEWMA control chart on $\lambda_{1}$ has many out of control data. Therefore, choose weight from range of 0.5 1 with bisection method, and will be obtained $\lambda_{2}=0.75$. Because the result of MEWMA control chart on $\lambda_{2}$ has many out of control data, choose weight from range of $0.75-1$ to find $\lambda_{3}$. Determined $\lambda$ by using bisection method until the result of MEWMA control chart is in control. MEWMA control chart as shown below:

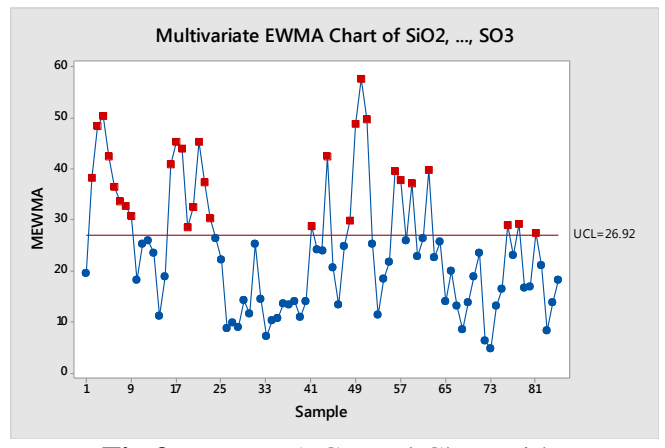

Fig.3. MEWMA Control Chart with $\lambda_{1}=0,5$

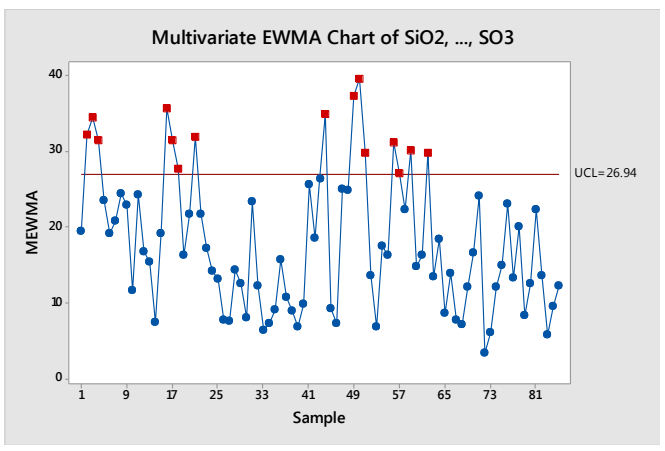

Fig.4. MEWMA Control Chart with $\lambda_{2}=0,75$ 


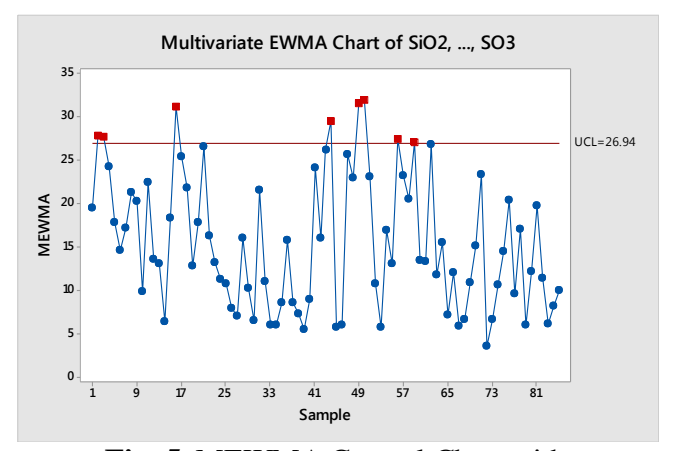

Fig. 5. MEWMA Control Chart with $\lambda_{3}=0,875$

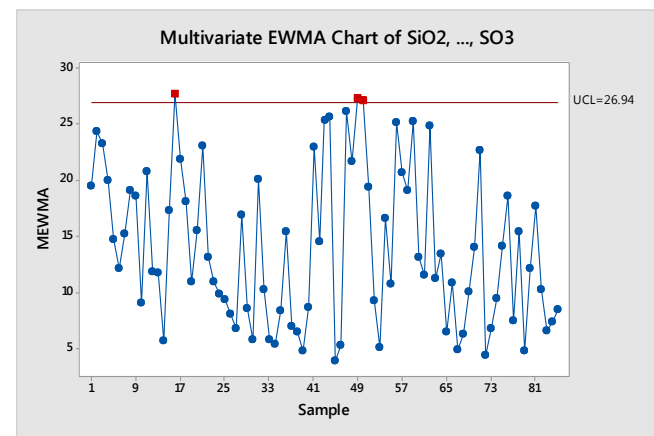

Fig.7. MEWMA Control Chart with $\lambda_{5}=0.96875$

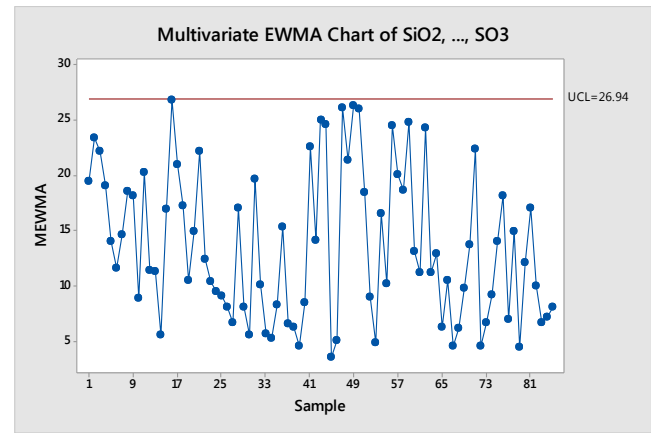

Fig. 9. MEWMA Control Chart with $\lambda_{7}=\mathbf{0 . 9 9 2 1 8 7 5}$

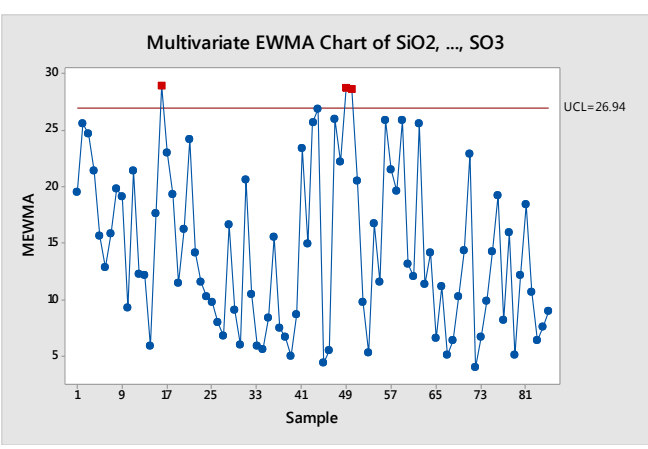

Fig. 6. MEWMA Control Chart with $\lambda_{4}=0,9375$

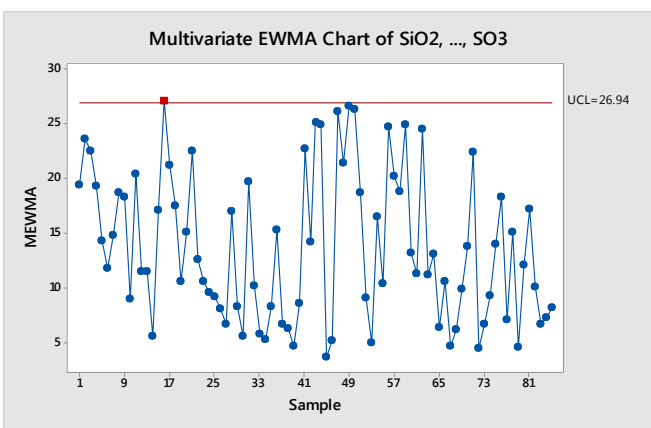

Fig. 8. MEWMA Control Chart with $\lambda_{6}=0.984375$

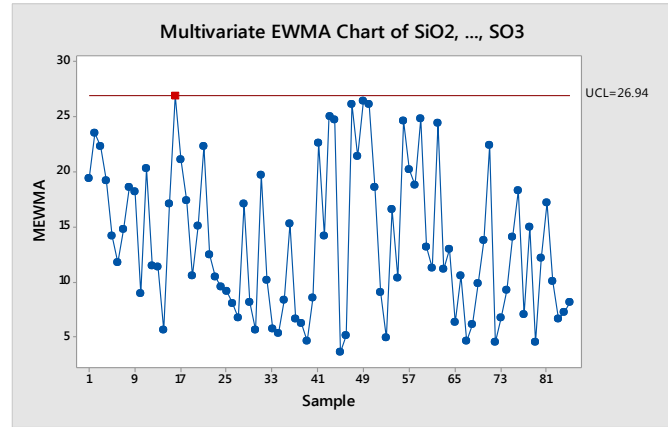

Fig. 10. MEWMA Control Chart with $\lambda_{8}=0.98828125$

From the figure 3 until 10, it has been obtained $\lambda_{1}$ is out of control data, $\lambda_{2}$ is out of control data, $\lambda_{3}$ is out of control data, $\lambda_{4}$ is out of control data, $\lambda_{5}$ is out of control data, $\lambda_{6}$ is out of control data, $\lambda_{7}$ is in control data and $\lambda_{8}$ is out of control data. Therefore, the observation was stopped in weight was $\lambda_{7}=0.98828125$, because there is one out of control data. Finally, by using the bisection method has $\lambda_{7}=0.9921875$ as the optimal weight of MEWMA control chart without out of control data. 


\section{Implementation of EWMA Control Chart}

EWMA control chart was firstly introduced by [5] and it is used to monitor the process and detects the causes existence of a continuous shift in a process. EWMA control chart is primarily used to detect any shift in the mean value of the process. EWMA control charts are widely used for forecasting time series data.

Let $x_{i}$ is observation value is observation to- $i$ where $i=1,2,3, \ldots$ is time or observation. EWMA values defined as follow:

$$
z_{i}=\lambda x_{i}+(1-\lambda) z_{i-1}
$$

EWMA control chart was created by plotting $z_{i}$, where $i=1,2,3 \ldots m$ of observation. The center line of EWMA control chart can be seen as follows:

$$
\text { Center line }=\mu_{0} \text {. }
$$

$\mu_{0}$ is assumed as $\bar{x}$.

Upper and Lower Center Line for EWMA control chart for each time is:

$$
\begin{aligned}
& U C L_{i}=\mu_{0}+L \sigma \sqrt{\left(\frac{\lambda}{2-\lambda}\right)\left[1-(1-\lambda)^{2 i}\right]} \\
& L C L_{i}=\mu_{0}-L \sigma \sqrt{\left(\frac{\lambda}{2-\lambda}\right)\left[1-(1-\lambda)^{2 i}\right]}
\end{aligned}
$$

After uses MEWMA control chart, will be uses EWMA control chart to controlling each of major component PCC of cement product. The $\mathrm{ARL}_{0}$ value that will be used is equal to $\mathrm{ARL}_{0}$ value for MEWMA control chart.

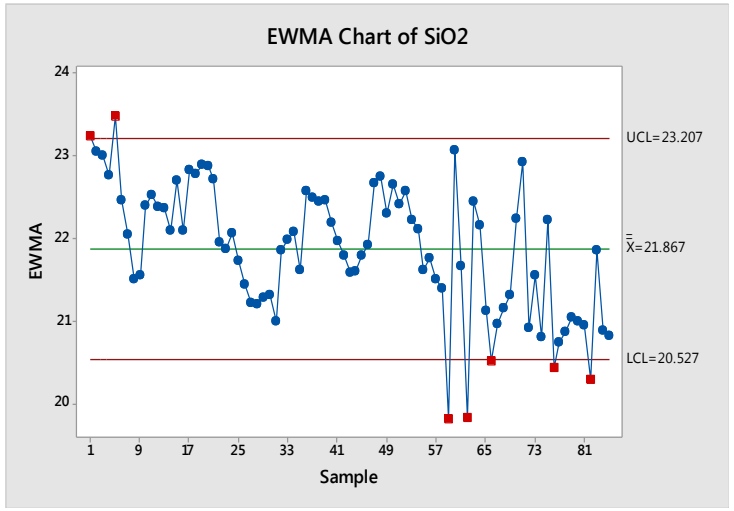

Figure 11. EWMA Control Chart of $\mathrm{SiO}_{2}$

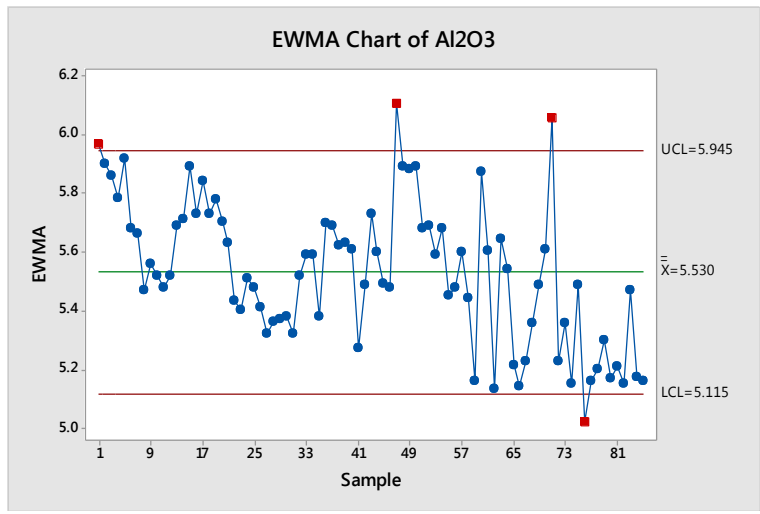

Figure 12. EWMA Control Chart of $\mathrm{Al}_{2} \mathrm{O}_{3}$ 


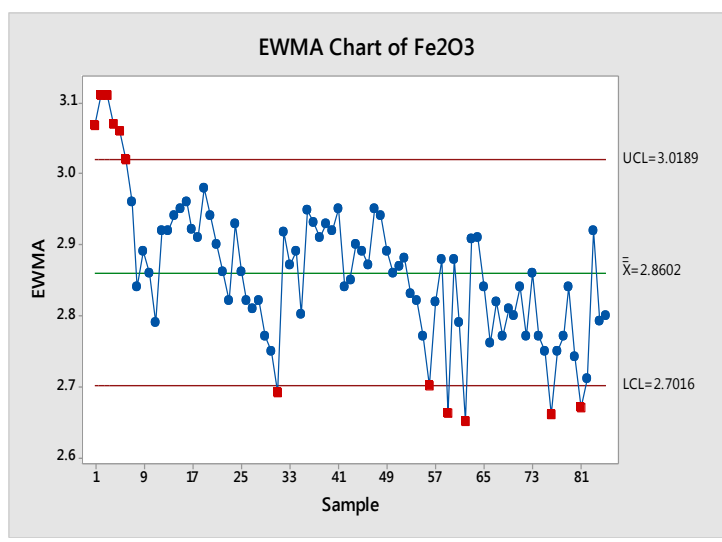

Fig. 13. EWMA Control Chart of $\mathrm{Fe}_{2} \mathrm{O}_{3}$

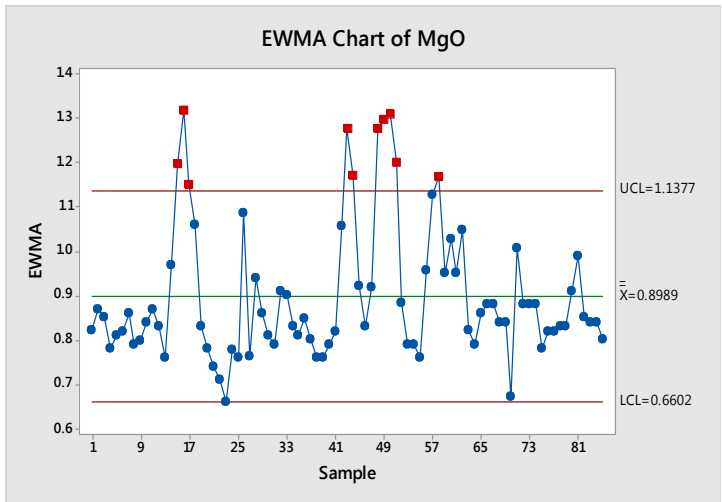

Fig. 15. EWMA Control Chart of $\mathrm{MgO}$

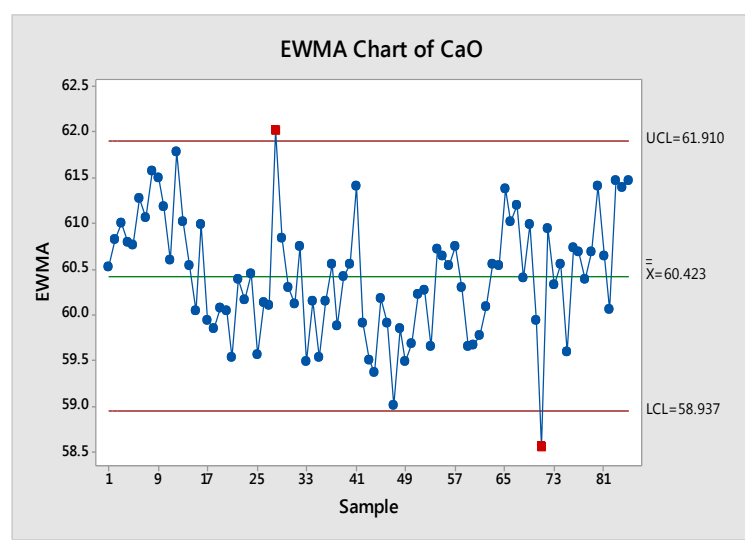

Fig. 14. EWMA Control Chart of $\mathrm{CaO}$

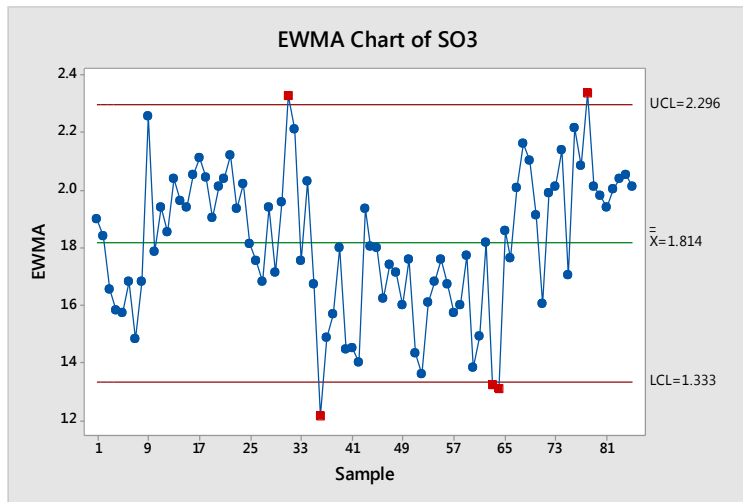

Fig. 16. EWMA Control Chart of $\mathrm{SO}_{3}$

From the figure above, known the major component control by using EWMA control chart in each variable consist of out of control data. In the EWMA control chart $\mathrm{SiO}_{2}$ has seven out of control data. In EWMA control chart for $\mathrm{Al}_{2} \mathrm{O}_{3}$ has four out of control data. In EWMA control chart for $\mathrm{Fe}_{2} \mathrm{O}_{3}$ has 12 out of control data. In EWMA control chart for $\mathrm{CaO}$ has two out of control data. In EWMA control chart for $\mathrm{MgO}$ has 10 out of control data and in EWMA control chart for $\mathrm{SO}_{3}$ has five out of control data.

\section{Result and Discussion}

Using the MEWMA control chart, the major component of PCC cement production has no data out of control at $\lambda_{7}=0.9921875$. By choose $\mathrm{ARL}_{0}$ and weight are same as before, will be identified generalized variance control chart for the data. The following control chart is 


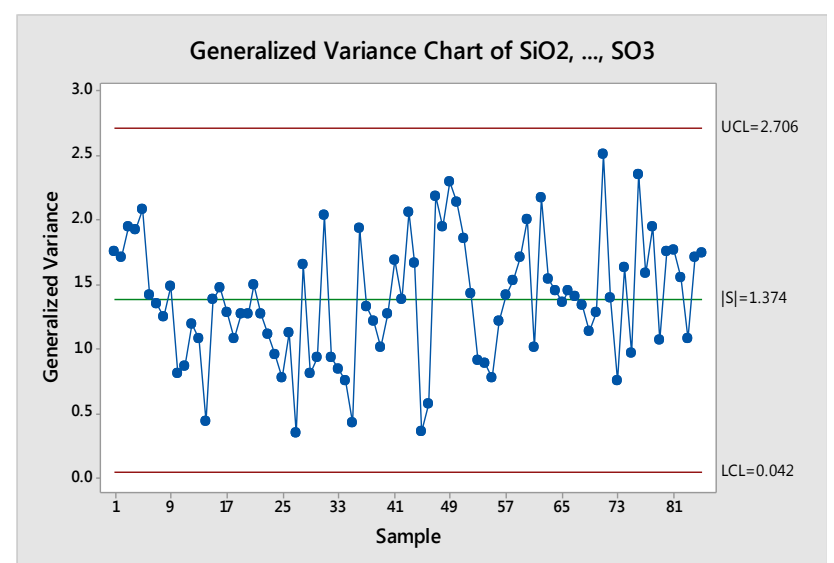

Fig 17. Generalized Varians Control Chart

The control chart is based on a generalised sample variance (the sample generalized variance) which is a determinant of the covariance matrix of the sample used to measure dispersion in multivariate. From the chart above with the $U C L=2.706,|S|=1.374$ and $L C L=0.042$, it known the major component of PCC cement production is at the limit control. So the conclusion that the prepared data are within the boundaries of the control. So that data variation is still located within the limits of safety.

The explanation is supported by outliner that is identified from each data variable.

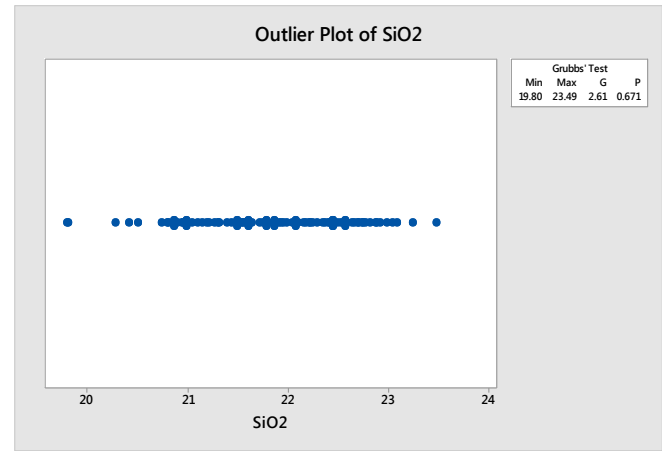

Fig. 18. Outlier of $\mathrm{SiO}_{2}$

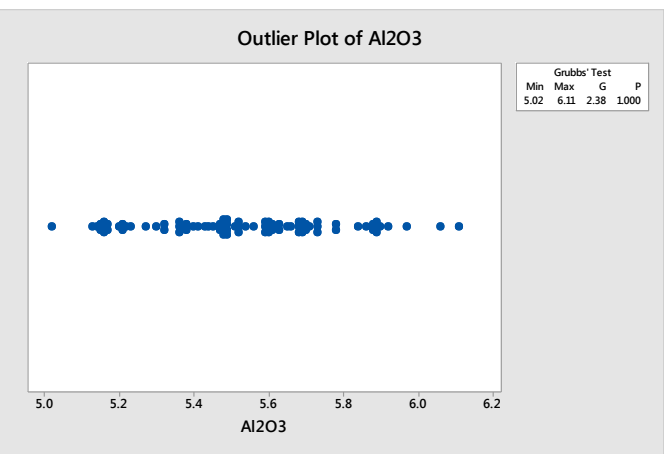

Fig. 19.Outlier of $\mathrm{Al}_{2} \mathrm{O}_{3}$ 


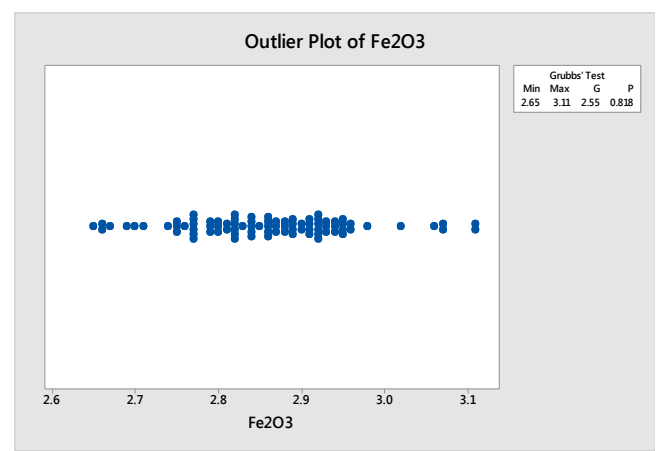

Fig.20. Outlier of $\mathrm{Fe}_{2} \mathrm{O}_{3}$

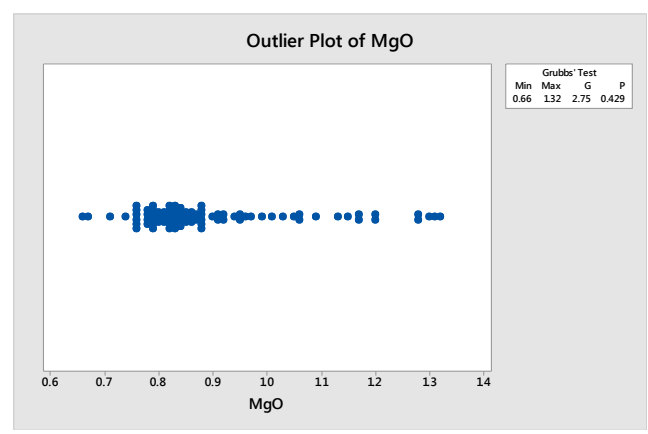

Fig. 22. Outlier of $\mathrm{MgO}$

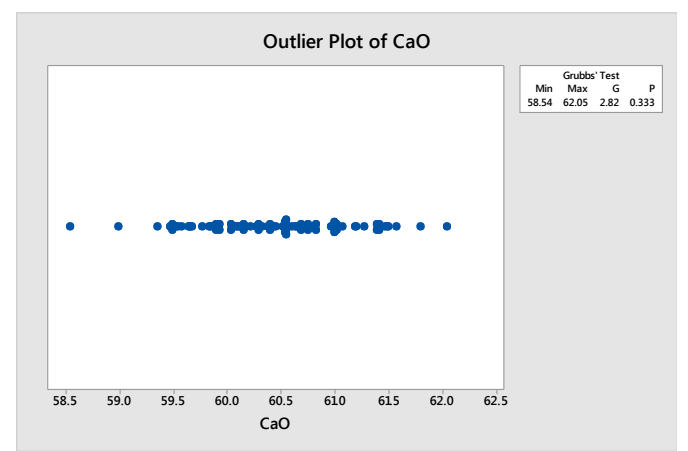

Fig. 21.Outlier of $\mathrm{CaO}$

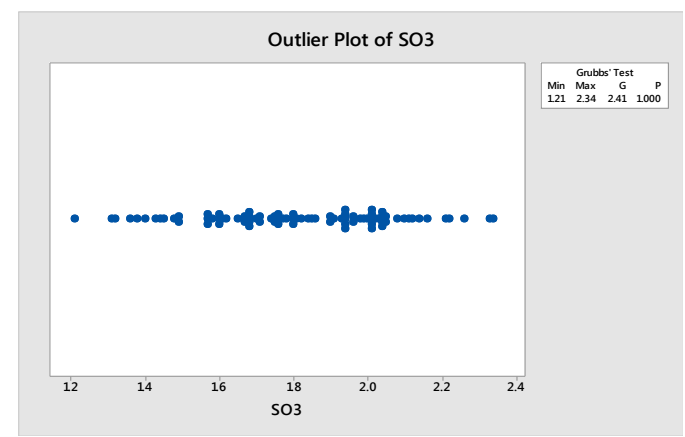

Fig. 23. Outlier of $\mathrm{SO}_{3}$

Based on the figure 18 until 23, it shows that the do not have outlier data. So, the data variety is not correct.Therefore, the data in each major component of cement product do not have the far different from the most other values in observation.

From the secondary data obtained and confirmed with the company of cement, it is known that secondary data used in this research is still needed as a process of improving the quality of the next improvement. To cover the bad quality in one particular observation, cement company trying to improve the quality on the next period. A major component in cement produced per day will be collected in silo and mix with a certain air pressure. In other that, the uncontrolled major component on certain day will be improved its quality by mixing the major component of the cement. It causes the quality of the cement will be well-maintained when the cement is in the silo will be processed to the next process.

\section{Conclution}

MEWMA control chart in controlling major component of PCC cement product gives 85 points in control data on parameter $\lambda 7=0.9921875$ as the optimal weight of MEWMA control chart. So decreasing the parameter $\lambda$ will be increase the performance of the MEWMA control chart. Therefore parameter $\lambda_{7}=0.9921875$ is the optimal parameter to determine best of MEWMA control chart. However, EWMA control chart for each variable in the data still has out of control for most of the major data, but the outlier were identified for each major component have not far different value of each variable. It is also a major component of data 
variation under control after a test with variance diagram control. The company of cement has to provide more information for controlling the quality, so that the quality of the cement produced are well maintained.

\section{References}

[1] Pers Conference.: First Quarter Financial Performance Report. Indonesian Cement, Jakarta (2019)

[2] Prabhu. S. S. dan Runger. G. C.: Designing a Multivariate EWMA Control Chart. Journal of Quality Technology, Vol. 29, pp. 8-15 (2018)

[3]Lowry, C.A., Woodal, W.H., Champ, C.W and Rigdon, S.E.: A Multivariate Exponentially Weighted Moving Average Control Chart. Technometrics. Vol. 34, pp. 4653 (1992)

[4]Borror. C. M., Montgomery. D. C. dan Runger. G. C.: Robustness of the EWMA Control Chart to Non-Normality. Journal of Quality Technology. Vol. 31, pp. 309-316 (2018)

[5] Khan. N., Aslam. M. dan Jun. C.: A EWMA Control Chart for Exponential Distributed Quality Based on Moving Average Statistics. Wiley online Library (2015)

[6]Devianto, D.: On the Class of Infinitely Divisible Exponential Distribution. Journal of Physics: Conference Series. Vol. 1097012084 (2018)

[7]Devianto, D.: The Uniform Continuity of Characteristic Function from Convoluted Exponential Distribution with Stabilizer Constant. AIP Conference Proceedings 1707. pp. $1-5(2016)$

[8] Devianto, D. ,Maiyastri, L. Oktasari and M. Anas.: Convolution of Generated Random Variable from Exponential Distribution with Stabilizer Constant. Applied Mathematical Sciences, Vol. 9 (96), pp. 4781-4789 (2015)

[9] Devianto, D., L. Oktasari and Maiyastri.: Some Properties of Hypoexponential Distribution with Stabilizer Constant. Applied Mathematical Science, Vol.9 (142), pp. 7063-7070 (2015)

[10]Conerly. M. D.: Multivariate Exponentially Weighted Moving Average (MEWMA). Wiley Statistics Reference Online (2014)

[11]Moraes. D. A O., Oliveira. F. L. P. dan Duczmal. L. H.: On the Hotteling's T, MCUSUM and MEWMA Control Chart's Performance with Different Variability Sources: A Simulation Study. Brazillian Journal of Operations \& Production Management. Vol. 12, pp. 196-212. (2015)

[12]Mahmoud, M.A and P.E., Maravelakis.: The Permormance of The MEWMA Control Chart when Parameters are Estimated. Communication in Statistics Simulation and Computation.Vol. 39, pp. 1803-1817 (2010)

[13] Hajlaoui, M.: On the Charting Procedures: MEWMA Chart and DD-Diagram. Open Journal of Statistics. Vol. 5, pp. 373-381 (2015)

[14]Amiri, A., Hamed. M and Mohammad, H. D.: Multi Objective Economic Statistical Design of MEWMA Control Chart.International Journal Productivity and Quality Management. Vol. 11, pp. 131-149 (2013)

[15]Hamed, MS.: Average Run Length Performance for Multivariate Exponentially Weighted Moving Average Control Chart Procedure with Application. International Journal of Computing and Optimization. Vol. 3, pp. 33-61 (2016)

[16] Knoth, S.: ARL Numerics for MEWMA Charts.Journal of Quality Technology. Vol. 49, pp. 78-89 (2017) 